\title{
CROSS-CULTURAL CONFLICT
}

\author{
Kevin Avruch \\ Institute for Conflict Analysis \& Resolution (4D3), George Mason University 3330 \\ Washington Blvd., Arlington VA 22201 USA
}

Keywords: conflict, individuals, cultural, groups, resolution, resources, communicational, orientation

\section{Contents}

1. The Nature of Conflict

2. Culture

3. Cross-Cultural Conflict

4. Culture, Identity, and Conflict

5. Culture, Ethnicity, and Ethnic Conflict

6. Cross-Cultural Conflict Resolution

Glossary

Bibliography

Biographical Sketch

\section{Summary}

Conflict is competition by groups or individuals over incompatible goals, scarce resources, or the sources of power needed to acquire them. This competition is also determined by individuals' perceptions of goals, resources, and power, and such perceptions may differ greatly among individuals. One determinant of perception is culture, the socially inherited, shared and learned ways of living possessed by individuals in virtue of their membership in social groups. Conflict that occurs across cultural boundaries thus is also occurring across cognitive and perceptual boundaries, and is especially susceptible to problems of intercultural miscommunication and misunderstanding. These problems exacerbate the conflict, no matter what the root causes of it -including strictly material interests-may be. In this sense culture is an important factor in many sorts of conflicts that at first may appear to be exclusively about material resources or negotiable interests.

In addition to framing the contexts in which conflict is understood and pursued by individuals, culture also links individual identities to collective ones. This fact is important in understanding the basis of most ethnic or nationalist conflicts, in which selected cultural material is utilized to constitute special sorts of social groups, those based upon putative (and primordial) ties of shared kinship, history, language, or religion.

Understanding the impact of cultural difference is especially important for analysts or practitioners of conflict resolution who work in intercultural contexts, since culture affects many of the communicational or interlocutory processes that lie at the heart of most conflict resolution techniques. Finally, because of increasing transnational exchanges, the coming century will see many more encounters among individuals of all 
backgrounds that are intercultural in nature.

\section{The Nature of Conflict}

Conflict is a feature of all human societies, and potentially an aspect of all social relationships. However, ideas about the root causes of conflict differ widely, and how one conceives of conflict determines to a large degree the sorts of methods we ultimately design to manage or resolve it. One conception of conflict roots it in the material world, as competition between individuals or groups over incompatible goals or scarce resources, or over the sources of power needed to reach those goals or control these resources, including the denial of control to others. A different conception locates the basic causes of conflict not so much in material scarcity as in divergent perceptions or beliefs about the nature of the situation, the other party, or oneself. The first orientation to conflict (and the world) is sometimes called "realism," the second "constructivism." But these terms, and the dichotomous way of thinking they enjoin, in actuality mask a great deal of social and behavioral complexity, both about the nature of conflict and about the possibilities for managing or resolving it.

One key to understanding the complexity of conflict and, ultimately, conflict resolution is to be found in the insight that many conflicts do not involve parties in unbridled, allout competition with a "winner takes all” mentality. Often conflicting parties find areas where cooperation is valued and sought after, even if it is only the cooperation inherent in keeping the basic relationship between them a continuing and viable one. Many conflicts, therefore, involve "mixed motives" (competition and cooperation). A second and equally important insight is that most conflicts are some combination of competition over goals or resources and the perceptions, beliefs, or values that the parties bring to the competition. For any given conflict, what matters is that parties believe or perceive themselves to be divided over goals, or believe or perceive the resources to be scarce, since parties will in the event act on the basis of their beliefs and perceptions.

According to realist conceptions, when resources are "objectively" scarce the course of conflict is limited to a few possible outcomes. An important variable in realist thinking is power. If there are significant imbalances of power between the parties, then one party yields to the other-the weaker to the stronger. This can occur following some overt test of strength (say, a war), or as the result of preemptive action-exit or surrender--by the weaker party. If the power of the two parties is more evenly balanced, however, then realist thinking expects some sort of negotiation to occur, for example compromise or distributive bargaining, such that resources are shared at some minimal level of mutual satisfaction. (Alternatively, in place of bargaining, one or both parties may seek to gain a power advantage through forming alliances with other parties.) One goal of "conflict resolution" in this mode is to encourage verbal or other symbolic bargaining to take place in lieu of a physical contest involving violence. A more advanced form of conflict resolution entails bringing the parties from purely distributive bargaining to integrative problem-solving, where the parties maximize their joint gains rather than settle for minimizing respective losses (or simply "split the difference" at some notional midpoint, as in compromise). But in any case, whether with contentious, distributive, or integrative outcomes, in its "purest" form (best modeled in some forms 
of game-theory), realist thinking on conflict assumes that all the parties share precisely the same metric for objectively measuring (perceiving) the main parameters of the contest, such as power, resources, and scarcity. In other words, realists assume that everyone understands these things in the same way.

By contrast, in the case where "subjectivity" of one sort or another enters the picturewhere the parties' perceptions of key parameters (power, resources, scarcity) of the contest differ significantly, so that everyone does not understand the world in the same way-then while the ensuing conflict may look the same (resulting in physical violence or war, for example), the prescription for conflict resolution looks very different. Now those committed to resolution must be concerned with such problems as cognitive or perceptual distortions, failures to communicate, or other sorts of communicational, interlocutory, or interpretive dysfunction.

It is important to caution that not all (perhaps not even most) conflicts can be boiled down simply to failures of communication or mutually faulty interpretation. But neither should it be assumed that all conflicts are always simply about objective scarcity between parties who always share the same understanding of the world. Nor should it be assumed that even if perceptions of scarcity are shared, that communication between the parties is unproblematic or "transparent." This means that conflict analysts and those committed to conflict resolution must pay attention to any factors that potentially impede or complicate communication between parties.

It is the combination of both objective and subjective dimensions that makes social conflict complex. Analytically, the proportional "mix" of these dimensions is always an empirical question, as it varies from conflict to conflict, party to party, and occasion to occasion. With respect to the practice of conflict resolution, it is in the "space" between the objective bases of conflict and the parties' subjective (or, more precisely, "intersubjective") understandings of the conflict that a good deal of contemporary conflict resolution does its work. For it is unlikely that parties will ever get any bargaining done, distributive much less integrative if, lacking common metrics, they occupy significantly different perceptual universes.

An analytical language or discourse is necessary for talking about both sorts of conflict and conflict resolution. The wholly "objective" sort is well served by the powerful discourse derived from neoclassical economics. Here one speaks of, among other things, utility functions, optimization, and maximization; and one presumes a universal model of decision-making based on universal principles of rational choice. The "intersubjective" orientation to conflict and conflict resolution, stressing communication, interpretation, and the possibility of diverse metrics for decisionmaking, needs another language. Historically, one candidate is the discourse of culture, which stresses cultural description and analysis.

\section{Culture}

Partly because it has come down from the nineteenth century with very different usages and meanings, the concept of "culture" is complicated. Nevertheless, one of the things that all contemporary social scientific definitions of culture have in common is that for 
none of them is culture connected primarily to "high art," advanced education, superior knowledge, exalted social standing, refinement, or "taste." (This, indeed, is one of the main nineteenth century meanings of the term that has so confused contemporary usage.) For no anthropologist, certainly, is "culture" something possessed only by the upper classes. Everyone "has" culture. In fact, everyone "has" potentially several cultures - this is yet another reason why the concept is complicated. Very generally, culture may be defined as socially inherited, shared, and learned ways of living possessed by persons by virtue of their membership in social groups.

To this broad definition must be added the observation that culture is always manifested in two ways, sometimes called generic and local. Generic culture is an attribute of all humankind, an adaptive feature of our species on this planet for at least a million years or so. Generic culture directs attention to universal attributes of human behavior, to "human nature." In contrast, local culture refers to those complex systems of meanings (encoded in symbols, schemas, and other sorts of cognitive representations) created, shared, and transmitted (socially reproduced and inherited) by individuals in particular social groups, at particular points in time. Local culture directs attention to diversity and difference. Most contemporary discussions of culture stress the local sense, focusing on difference. Certainly, this is the sense in which people usually connect culture to conflict. But it is important to remember that culture also represents generic or universalistic capabilities, especially when one moves from conflict to conflict resolution. For example, all human beings, regardless of what "local" language they happen to speak, possess the universal or generic capacity of language acquisition. Some people acquire fluency in several different languages. This means that translation between languages is possible, even as locally spoken languages may separate language-communities and speakers from one another. Following the language analogy, just as individuals may attain varying degrees of fluency in a number of languages throughout their lives (multilingualism), so too is "multiculturalism" (in the sense of fluency or "competence" in a number of different local cultures) possible. And so too is "translation" across local cultural boundaries. More than possible, it is more widespread and common than many people believe. This is in fact one sense in which people may "have" several cultures.

There is at least one other point about culture to be made from an analogy to language. A cursory comparison between the English of Shakespeare's time and that spoken today demonstrates that languages change through time. Similarly, the English of London's East End and Manhattan's Lower East Side, as spoken today, are not identical. No language is immutable across time and space, or insensitive to external influencedespite what many linguistic chauvinists would like to believe about "their" language. Culture, too, is dynamic, not timeless or changeless-regardless of what cultural chauvinists might like to proclaim. The implications of cultural change for conflict are varied. On the one hand, the susceptibility of culture to (sometimes rapid and deep) change can lead to social instability, and this may in turn lead to conflict. On the other hand, possibilities for change mean that cultures may prove adaptive to new situations, and that individual bearers of local cultures may use cultural resources to accommodate to change (or to bring about positive change), and respond to potential conflict in prosocial ways. History, of course, provides examples of both possibilities. Histories of social conflict, especially those steeped in violence and war, highlight the first set. 
Those committed to peaceful conflict resolution would like to see in the future more history reflecting the second, adaptive and prosocial, use of and response to cultural change.

\section{TO ACCESS ALL THE 12 PAGES OF THIS CHAPTER, Visit: http://www.eolss.net/Eolss-sampleAllChapter.aspx}

\section{Bibliography}

Avruch K. (1998). Culture and Conflict Resolution, 153 pp. Washington, DC: United States Institute of Peace Press. [This brings to bear contemporary culture theory on the analysis of conflict and conflict resolution practice.]

Avruch K., Black P., and Scimecca J., eds. (1998). Conflict Resolution: Cross-Cultural Perspectives, 244 pp. New York: Praeger. [A collection of original essays examining conflict and conflict resolution techniques in a number of different cultural settings.]

Cohen R. (1990). Culture and Conflict in Egyptian-Israeli Relations: A Dialogue of the Deaf, 206 pp. Bloomington, IN: Indiana University Press. [This analyzes communication-based problems in EgyptianIsraeli diplomatic relations due to mutual cultural misunderstanding.]

Docherty J. S. (2001). Learning Lessons from Waco: When the Parties Bring their Gods to the Negotiation Table, 310 pp. Syracuse, NY: Syracuse University Press. [This analyzes the failed negotiations in 1993 between Branch Davidians and the FBI as due to fundamental cultural conflicts between different world views.]

Druckman D. (1996). Is there a US negotiating style? International Negotiation 1(2), 327-334. [This examines critically the notion of "national negotiating styles" with special reference to American diplomacy.]

Eller J. D. (1999). From Culture to Ethnicity to Conflict: An Anthropological Perspective on International Conflict, 360 pp. Ann Arbor, MI: University of Michigan Press. [This analyzes the relationship of culture to ethnicity in the formation of ethnic groups in conflict.]

Hall E. T. (1976). Beyond Culture, 298 pp. New York: Anchor Books. [This explores some of ways "beyond" culture and language by which humans experience and categorize their worlds.]

Huntington S. P. (1996). The Clash of Civilizations and the Remaking of World Order, 367 pp. New York: Simon and Schuster. [This postulates global conflict occurring along the fault-lines separating six or seven world "civilizations" as characterizing the coming century.]

Ross M. H. (1997). Culture and identity in comparative political analysis. Comparative Politics: Rationality, Culture, and Structure, (ed. M. Lichbach and A. Zuckerman), pp. 42-80. New York: Cambridge University Press. [This analyzes some ways in which culture frames the social and political contexts in which conflict is pursued, and how it also provides for individuals key linkages between individual and collective identities.]

Volkan V. D. (1999). Blood Lines: From Ethnic Pride to Ethnic Terrorism, 280 pp. Boulder, CO: Westview Press. [This explores ethnic violence by examining history and diplomacy from a psychoanalytic perspective.] 


\section{Biographical Sketch}

Kevin Avruch is a Professor of Conflict Resolution and Anthropology at the Institute for Conflict Analysis and Resolution (ICAR), and a senior fellow in the Program for Peacekeeping Policy, School of Public Policy, at George Mason University. Educated at the University of Chicago and the University of California, San Diego, his books include American Immigrants in Israel: Social Identities and Change (1981), Conflict Resolution: Cross-Cultural Perspectives (1991/1998, coeditor), Critical Essays on Israeli Society, Religion, and Government (1997, coeditor), Culture and Conflict Resolution (1998), and Information Campaigns for Peace Operations (1999). He was a 1996-1997 fellow in the Jennings Randolph Program for International Peace at the United States Institute of Peace. 